\title{
Críticas construtivas de formandos em Odontologia para o repensar do estágio supervisionado no SUS
}

\author{
Cristina Berger Fadel*; Marcos Vinícius de Sousa Pereira**; Kérolen Cristina Moura**; Alessandra \\ de Souza Martins*; Márcia Helena Baldani Pinto*
}

* Docente, Departamento de Odontologia, UEPG
** Egresso(a), Curso de Odontologia, UEPG

Recebido em 26/05/2018. Aprovado em 20/12/2018.

\begin{abstract}
RESUMO
O estudo visa obter percepções críticas de formandos em Odontologia sobre o estágio curricular no SUS. Realizou-se pesquisa exploratória, descritiva e qualitativa junto à população de acadêmicos concluintes do curso de Odontologia de uma universidade pública do sul do Brasil $(n=52)$ (ano base: 2016), considerando-se para fins de análise somente os acadêmicos que julgaram que o estágio no SUS não foi produtivo para a sua formação acadêmica $(n=11)$. A apreensão das informações se deu por meio de questão norteadora única e os resultados foram tratados de acordo com a técnica de análise do discurso do sujeito coletivo. Das informações obtidas foram extraídos dois temas 'Organização' e 'Estrutura' do estágio, e sete ideias centrais, as quais deram origem aos discursos. Os acadêmicos expõem importância arraigada ao modelo de atuação profissional tecnicista, com baixo interesse no SUS enquanto campo de trabalho.

Descritores: Odontologia. Sistema Único de Saúde. Avaliação Educacional. Pesquisa Qualitativa.
\end{abstract}

\section{INTRODUÇÃO}

O campo da formação profissional dos cursos de ciências da saúde, nos tempos atuais, passa por um acelerado processo de mudanças em sua estrutura curricular, sob a perspectiva da formação interdisciplinar como elemento central das práticas de construção e compartilhamento do conhecimento no ensino superior. Sabe-se que a compartimentalização dos conhecimentos em disciplinas isoladas, espaços singulares e específicos de aprendizagem não respondem mais às novas demandas e possibilidades de aprendizagem, e este fato, passa a exigir das instituições de ensino uma visão mais abrangente, global e interdisciplinar a 
respeito dos conhecimentos e da realidade ${ }^{1,2}$.

Neste contexto de reinvenção e redefinição das universidades brasileiras, o campo da saúde é provocado na direção de formar profissionais com perfil humanista, capazes de atuar na integralidade da atenção à saúde e em equipe, características indispensáveis aos serviços do Sistema Único de Saúde (SUS), considerando também as Diretrizes Curriculares Nacionais (DCN) $)^{3,4}$. Desta forma, após as primeiras publicações das DCN para os cursos da saúde, em 2001, políticas públicas específicas à formação superior começaram a ser implementadas e vinculadas de forma explícita ao sistema de saúde vigente no país, visando à formação de uma ampla rede de ensino e aprendizagem. Como estratégias colaboradoras da qualificação da formação no campo da saúde fomentadas pelo governo brasileiro, destacam-se, em especial, o Programa Nacional de Reorientação da Formação Profissional em Saúde (PRO-Saúde) e o Programa de Educação pelo Trabalho para a Saúde (PET-Saúde). Cabe aqui, porém, uma consideração ressaltando que a ordenação da formação de recursos humanos na área de saúde havia sido anteriormente incluída no campo de atuação do SUS pela lei 8080/90 .

Especificamente na Odontologia, este desafio de compor e acompanhar os movimentos de reformulação das diretrizes da educação profissional em saúde ${ }^{6-9}$ vem sendo calçado pela integração entre ensino e serviço, privilegiando espaços que extrapolem os limites físicos das instituições e onde os acadêmicos possam potencialmente realizar habilidades extra clínicas, considerando as demandas biopsicossociais de seu trabalho ${ }^{10-13}$. Nesta direção, ganha força a premissa do estágio supervisionado, compreendido como uma das práticas de maior potencial transformador por inserir os alunos em cenários reais do SUS na realidade social e econômica de sua região, e nas práticas e políticas em saúde pública $^{14}$. A partir desse contexto, a formação odontológica passa a ser participante de uma rede formativa de integração, deixando de pensar as articulações com o SUS como um tema marginal.

O curso de Odontologia em tela é constituído por duas vertentes disciplinares: uma direcionada à formação específica profissional, com um total de 3.655 horas, e o estágio curricular supervisionado, com 1.037 horas. As disciplinas da base curricular do curso são distribuídas por matérias anuais e semestrais, com envolvimento integrado entre teoria e prática.

De acordo com o arranjo de ensino, a área da Saúde Coletiva (SC) é subdividia em três momentos de aprendizagem: SC I, II e III. A disciplina de SCI atua principalmente no campo da etiologia e prevenção de doenças bucais; a SCII dentro dos preceitos da epidemiologia e políticas públicas de saúde, com caráter voltado à ciência e construção de ferramentas teóricas e metodológicas necessárias ao planejamento e administração de serviços públicos de saúde; e a SCIII, refere-se especificamente às práticas no Sistema Único de Saúde, por meio de estágio curricular obrigatório. Este estágio ocorre no oitavo período do curso, com carga horária de 51 horas. Como método pedagógico, busca a integração entre o ensino da saúde e os serviços nas Unidades de Saúde da Família (USF), numa articulação entre o saber conviver, saber científico e popular almejando então uma experiência subjetiva e reflexiva de formação profissional.

A partir do exposto, o objetivo do presente estudo é analisar a percepção de acadêmicos formandos em Odontologia sobre o estágio supervisionado no SUS, enfatizando aspectos considerados contraproducentes, como subsídio para um novo processo de reestruturação curricular.

\section{METODOLOGIA}

Os acadêmicos foram abordados coletivamente, em sala de aula, em momento considerado propício e não havia limitação de tempo para que os participantes respondessem ao questionamento. Os participantes tiveram suas 
identidades totalmente preservadas.

Adotou-se o modelo de estudo exploratório descritivo, com abordagem qualitativa. A amostra foi constituída pela totalidade de acadêmicos concluintes do curso de Odontologia de uma universidade pública do sul do Brasil $(\mathrm{n}=52)$, não havendo restrições biossociais. $\mathrm{O}$ ano base para a consulta foi 2016. Para a apreensão das percepções dos formandos sobre o estágio curricular no Sistema Único de Saúde, os indivíduos responderam a um instrumento autoaplicável, composto por questão disparadora única: "Caso você considere que o estágio no SUS não tenha sido produtivo para a sua formação acadêmica, por favor, fale o que poderia ser desenvolvido e de que forma, visando o melhor aproveitamento desse estágio em sua vida profissional."

Como referencial metodológico para a tabulação das informações coletadas foi adotada a teoria das Representações Sociais, composta por elementos como crenças e opiniões, os quais são organizados a fim de expressar a realidade ${ }^{15}$ e a análise e apresentação dos resultados teve por base o Discurso do Sujeito Coletivo (DSC), proposto por Lefèvre $^{16}$. Este consiste na reunião, em um só discurso-síntese, de vários discursos individuais emitidos como resposta a uma mesma questão de pesquisa, por sujeitos social e institucionalmente equivalentes ou que fazem parte de uma mesma cultura organizacional e de um grupo social homogêneo. O método DSC busca então a criação de um vínculo entre senso comum e conhecimento científico partindo da reconstituição de um pensamento coletivo, fundamentado nas representações sociais.

Os relatos obtidos foram analisados para a identificação das expressões-chave de conteúdo similar, e identificação das ideias centrais (IC) para, posteriormente, formular-se uma síntese única originária dos discursos (DSC), onde o pensamento de um grupo ou coletividade aparece como se fosse um discurso individual. $\mathrm{Na}$ presente pesquisa os DSC seguem com indicação, entre parênteses, do número de acadêmicos formandos (AF) que corroboraram do mesmo pensamento ou percepção.

Os resultados oriundos de cada questão, a síntese das ideias centrais, juntamente com a proporção das respostas obtidas foram expostos também numericamente, respeitando-se a dupla condição qualitativa e quantitativa do objeto ${ }^{17,18}$. Todas as ideias compartilhadas entre os entrevistados em relação a cada questão e seus discursos foram descritos e discutidos com suporte da literatura científica.

O presente estudo obedeceu aos preceitos estabelecidos pela Resolução $n^{\circ}$ 466/12 do Ministério da Saúde e foi aprovado por Comitê de Ética em Pesquisa (Parecer CEP $n^{\circ}$ 1.821.264/16), sendo respeitados os aspectos relacionados com o anonimato total do entrevistado, sua privacidade e autonomia para aceitar ou não a participação no estudo. Todos os participantes assinaram Termo de Consentimento Livre e Esclarecido.

\section{RESULTADOS}

A amostra final foi constituída por 35 acadêmicos concluintes, com média etária de 22 anos, sendo a maioria mulheres. Destes 11 $(34,4 \%)$ afirmaram que o estágio no SUS não foi produtivo para a sua formação acadêmica, sendo então considerados para a presente pesquisa.

Das informações obtidas neste estudo foram extraídos dois temas: 'Organização da disciplina' e 'Estrutura da disciplina' e sete ideias centrais: 'disponibilidade do serviço e do cirurgião-dentista'; 'ampliação do contato com diferentes profissionais campos e processos de trabalho no SUS', 'ampliação do contato com a prática clínica odontológica'; 'suporte físico'; 'carga horária'; 'obrigatoriedade' e 'avaliação', as quais deram origem a onze DSC (tabelas $1 \mathrm{e}$ 2). 


\section{Tema um: Organização}

Atualmente a disciplina de SCIII segue a lógica de um estágio semidireto de observação e ação. Um grupo de, em média seis acadêmicos, é vinculado a um professor orientador de estágio e a um preceptor, representado pelo cirurgião- dentista (CD) de uma Equipe de Saúde Bucal, em uma das Unidades de Saúde da Família do município de referência.

A seguir, são expostas as opiniões críticas referentes à 'organização', dispostas em três ideias centrais, as quais deram origem aos discursos.

Tabela 1. Descrição do tema 'Organização', síntese das ideias centrais e proporção de respostas obtidas da questão disparadora $(n=11)$

\begin{tabular}{llc}
\hline TEMA 1 & IDEIAS CENTRAIS & \% \\
\hline \multirow{3}{*}{ Organização } & Disponibilidade do serviço de saúde e do cirurgião-dentista & 28,53 \\
& Ampliação do contato com diferentes profissionais, campos e processos & 1,4 \\
& de trabalho no SUS & \\
& Ampliação do contato com a prática clínica odontológica & 40,1 \\
\hline
\end{tabular}

Disponibilidade do serviço de saúde e do cirurgião-dentista

DSC - "Antes de começar o estágio deveria ser avaliado se a unidade realmente pode e o dentista quer e tem disponibilidade para acompanhar os estagiários, pois muitas ações não podem ser desenvolvidas por falta de disponibilidade de horário do $C D$ da unidade [...]. Eu acho que as unidades de saúde não inserem os estagiários na rotina, por isso essa avaliação prévia da disponibilidade e vontade do CD e da unidade é importante para que nenhum grupo seja prejudicado". (AF 3, AF 5, AF 7, $A F$ 10)

Adiante evidencia-se o descontento a respeito do inter-relacionamento pessoal e do acolhimento propiciado pelo serviço de saúde.

DSC - “[...] os CD participantes deveriam ser instruídos a tratar todos os alunos de forma igual... uns (alunos) tinham que fazer sozinhos, outros $(C D)$ davam extrema atenção [...]. Falta empatia e melhor compreensão entre o dentista e os participantes do grupo. Acho que falta vontade de contribuição e comprometimento para o estágio por parte das unidades de saúde, do CD e equipe”. (AF 2, AF 6, AF7, AF 11)

$\mathrm{Na}$ sequência, evidencia-se o anseio acadêmico pela ampliação dos processos multiprofissionais e interpessoais no sistema de saúde.

Ampliação do contato com diferentes profissionais, campos e processos de trabalho no SUS DSC-"Os alunos deveriam desenvolver ações em vários dias da semana, a fim de conhecer todas as diferentes ações que estão sendo realizadas pela equipe de saúde da família. [...] acho que a divisão dos acadêmicos por cada categoria profissional, para ver as diversas realidades, favoreceria o relacionamento com o médico, enfermeiro, e demais membros da equipe, pois ficou mais restrito ao $C D$ e $A C S$ ". (AF 1, $A F$ 3, $A F$ 2)

DSC-"Conhecer como funciona as farmácias na atenção básica, 
acompanhamento dos pacientes atendidos pelas outras especialidades, maior contato e ações com os profissionais no NASF[...] Enfim... visitar vários pontos do SUS e, não somente uma região. Vemos apenas uma parte e não a integralidade ficando dentro $d a$ unidade”. (AF 11, AF 4, AF 5)

Abaixo, a ideia central mais prevalente deste tema, a qual legitima, entre os acadêmicos, a valorização do modelo formativo biologicista.

\section{Ampliação do contato com a prática clínica odontológica}

DSC - "Esta disciplina deveria desenvolver mais ações voltadas a nossa área, mesmo como estagiários poderíamos fazer mais dentro da odontologia. [...] acredito que o contato mais direto com o consultório odontológico, de uma maneira mais clínica, nos acrescentaria ainda mais. Seria bem mais relevante acompanhar toda a rotina do $C D$ na unidade e dar auxílio a ele nos atendimentos odontológicos". (AF 8, AF 6, AF 9, AF 11, AF 3)

\section{Tema dois: Estrutura}

A disciplina de Saúde Coletiva III, estágio curricular supervisionado, está em conformidade com regulamento aprovado pelo Conselho de Ensino, Pesquisa e Extensão, Resolução CEPE n ${ }^{\circ}$ 033, de 08/06/2010. Atualmente é desenvolvida no oitavo semestre do curso de Odontologia e conta com uma carga horária de 51 horas, divididas em doze semanas de atividades de dispersão e cinco semanas de contextualização intramuros. Nos momentos de dispersão o grupo de acadêmicos vivencia o cenário de Unidades de Saúde da Família (USF) e desenvolve ações pactuadas com professor e preceptor, fruto do trabalho de planejamento. Dentre as ações destacam-se práticas de educação em saúde para diferentes grupos sociais, inquérito epidemiológico em saúde bucal, reconhecimento do território de abrangência das unidades de saúde, conhecimento do funcionamento e processo de trabalho no SUS.

Os momentos de contextualização são programados de forma que os acadêmicos possam trazer para a sala de aula dificuldades e êxitos inerentes a ciclos comuns de atividades em campo, compartilhando a sua realidade com os demais estagiários.

Seguem as opiniões dos formandos a respeito da estruturação do estágio, dispostas em quatro ideias centrais, as quais deram origem aos discursos.

Tabela 2. Descrição do tema 'Estrutura', síntese das ideias centrais e proporção de respostas obtidas da questão disparadora $(n=11)$

\begin{tabular}{llc}
\hline TEMA 2 & IDEIAS CENTRAIS & \% \\
\hline \multirow{3}{*}{ Estrutura } & Suporte físico & 28,5 \\
& Carga horária & 22,8 \\
& Obrigatoriedade & 34,2 \\
& Avaliação & 14,5 \\
\hline
\end{tabular}

\section{Suporte físico}

DSC - "A universidade não oferece transporte para o local do estágio, não se responsabilizando no que pode acontecer.[...]como é um estágio obrigatório deveria ter (transporte), pois os 
lugares eram muito longe, a locomoção era difícil e os alunos eram expostos a situações de risco". (AF 4, AF 2, AF 9)

\section{Carga horária}

DSC - "O estágio deveria ser resumido em apenas uma ou duas semanas, no máximo, não há necessidade de um semestre para ver como uma unidade de saúde funciona[...]. Acho que as ações deveriam ser pontuais e não toda semana, com acompanhamento menor e mais superficial dos casos". (AF 1, AF 5)

DSC - "[...] poderiam diminuir o tempo, pois parece que estamos "atrapalhando" os profissionais no seu dia a dia....sinto que os alunos são mais um problema que uтa solução dentro da unidade de saúde". (AF 6, $A F 8$ )

\section{Obrigatoriedade}

DSC - "Essa matéria deveria ser optativa e não obrigatória, pois não quero trabalhar no SUS. [...] deveria ser somente para quem tem interesse e quer realmente seguir o ramo da saúde pública posteriormente. [...] ou o estágio poderia ser como um projeto de extensão, como o PET". (AF 6, AF 9, AF 1)

\section{Avaliação}

DSC - "[...] acho que os professores devem acompanhar em tempo integral os alunos, para facilitar o nosso contato com o CD e poder avaliar o que cada aluno faz, pois, muitas vezes o dentista não cria uma visão eficiente dos alunos [...]. A avaliação deveria ser feita pelos professores e não pelos dentistas da unidade...eu acredito que ele (CD) não tem conhecimento suficiente para avaliar um aluno da universidade." (AF 8, AF 1)
DSC - "Se a professora preceptora do estágio vai até a unidade para ver se estamos cumprindo as ações, não vejo necessidade de uma avaliação por parte do CD da unidade, pelo pouco contato. [...] quase não vêm (CDs) o que realizamos nas ações $e$ nem sabem $o$ quanto de conhecimento temos". (AF 6, AF 10, AF 5)

\section{DISCUSSÃO}

O estágio curricular no campo da Odontologia privilegia um cenário de aquisição e aprimoramento de conhecimentos e habilidades essenciais ao exercício profissional na saúde, cujo objetivo primeiro é a interação entre teoria e prática. Trata-se de uma experiência com dimensões formadoras, que proporciona ao acadêmico a participação em situações reais de trabalho, explorando competências básicas indispensáveis para a formação profissional.

Neste contexto, a função do preceptor é acolher o estagiário em seu universo de trabalho e articular ações junto aos demais membros da equipe de saúde e a comunidade, agindo como facilitador do efetivo desenvolvimento do estágio $^{19-21}$.

Em relação ao professor orientador, seu desempenho deve ser capaz de possibilitar unidade entre ensino e serviço, compondo uma rede de relações formativas. Na disciplina em tela, as ações a serem desenvolvidas são pactuadas com acadêmicos e preceptores, e divididas em dois momentos táticos: contextualização e dispersão. No momento de dispersão nos campos de estágio, os acadêmicos vivenciam o SUS por meio da interação com processos de trabalho de todos os membros da equipe de saúde da família, a saber: desenvolvimento de atividades educativopreventivas a diferentes grupos sociais, acompanhamento de profissionais em visitas domiciliares, reconhecimento do território de abrangência da unidade de saúde de referência, 
reconhecimento do processo de trabalho no SUS e realização de inquérito epidemiológico, sob acompanhamento efetivo pelo professor orientador e pelo preceptor, conforme a lei $\mathrm{n}^{\circ} 11.788$, de 25 de setembro de 2008, que dispõe sobre o estágio de estudantes $^{22}$.

Quanto ao momento de contextualização em sala de aula, acadêmicos inseridos em diferentes campos de estágio expõem as suas vivências e práticas, sendo estimulados pelo docente a relacionarem teoria e prática, exercitando o pensamento crítico e reflexivo.

As percepções apresentadas evidenciaram o descontentamento do grupo de acadêmicos analisados em relação à aceitação e ao empenho da unidade de saúde e do cirurgião-dentista preceptor, ratificam o interesse em uma maior aproximação com as diferentes categorias profissionais, campos e processos de trabalho no SUS, ao mesmo tempo em que indicam o interesse por uma maior participação na prática clínica odontológica dentro do estágio.

Profissionais da saúde pública são bastante afetados por fatores ocupacionais, visto que, em sua grande maioria, expõem-se a cargas de pressão no ambiente de trabalho e ao acúmulo de vínculos e exigências modernas, os quais podem influenciar seu desempenho e qualidade de vida. Somado a isso, encontra-se a falta de integração entre a programação da esfera municipal de saúde, ao absorver legalmente a demanda universitária para complementação do ensino, da aprendizagem e da participação acadêmica em situações reais de vida e trabalho, as programações locais (das unidades de saúde), ao não absorverem qualitativamente os estagiários em suas agendas e processos de trabalho. Esses dois aspectos do aparelhamento da saúde, disposição profissional e organizacional, parecem influenciar a imagem dos acadêmicos investigados sobre a organização do estágio, e responsabilizar possíveis diferenças em seu processo formativo.
De fato, as unidades de saúde representam um sítio privilegiado de observação e de análise do SUS, seja quanto às suas práticas médicas assistenciais ou quanto às suas práticas promotoras de saúde. Também, a inserção do acadêmico nestes ambientes possibilita a reflexão sobre o processo de trabalho em saúde e suas tecnologias, sobre as redes de atenção, e sobre o desenvolvimento de habilidades de comunicação e relacionais ${ }^{23-28}$. Desta forma, unidades de saúde (como campos de estágio), gestores, usuários e trabalhadores assumem papel estratégico na formação dos futuros profissionais.

Estudos apontam que esse desafio posto a docentes, trabalhadores, preceptores e estudantes da saúde visa também melhor significar o exercício de ser profissional na Estratégia Saúde da Família; e isto requer não somente a preparação de docentes e preceptores, mas também, a ressignificação de seus papéis e de suas práticas na concepção acadêmica atual ${ }^{29,30}$.

Como o estágio curricular no SUS é um processo relativamente novo, cabe, de um lado, o fortalecimento dos elos entre instituição de ensino e gestão municipal de saúde, e de outro, a experimentação do saber e fazer compartilhados entre docentes, alunos, usuários, preceptores e equipes de saúde.

No discurso relacionado a disponibilidade do serviço de saúde e do cirurgião-dentista fica evidente a percepção acadêmica voltada ao entendimento de vínculo restrito entre profissional e estagiário, e reforça a sensação de ausência de engajamento das equipes de saúde nos cenários de prática. Primeiro contato, vínculo e acolhimento são ferramentas essenciais para a construção de experiências profícuas entre profissionais e alunos, sendo esta uma estratégia humanizadora $\mathrm{e}$ integradora de práticas nos serviços, e detentora da troca de saberes.

O trabalho de modo integrado pressupõe uma valorização do grau de relação entre os 
agentes envolvidos, com vistas ao entendimento e ao reconhecimento recíproco de autoridades de saberes e de autonomia técnica ${ }^{31}$ sendo, conforme explicitado pelos sujeitos, fonte de insatisfação com o estágio.

Autores expõem que o trabalho interprofissional e acolhimento como tecnologias operacionais de ensino e aprendizagem estão em processo de construção, uma vez que sofrem alterações nos diferentes cenários do SUS, em razão dos níveis de concepções e das maneiras de se reorganizar o cotidiano nos serviços ${ }^{32-34}$.

A interdisciplinaridade, aqui entendida como a relação articulada entre as diferentes profissões das ciências da saúde, apresenta-se como um dos conceitos nucleares para consolidação das políticas públicas de saúde ${ }^{35}$, sendo apontada pelos entrevistados como prática determinante da qualidade do estágio. Por meio dela busca-se a substituição de uma concepção profissionalizante fragmentada do saber científico por uma concepção globalizada, indo além da aplicação de diferentes ângulos sobre determinados objetos de análise no campo profissional. Apesar da atuação interdisciplinar ser considerada central pelos docentes responsáveis pelo estágio no SUS, esta comunicação entre saberes e práticas profissionais das diferentes áreas, e ainda, o confronto e discussão de perspectivas distintas não foram observados pelos acadêmicos.

Outra questão destacada refere-se ao conhecimento prático das Redes de Atenção à Saúde (RAS). De fato, esta prática tem sido consolidada dentro da instituição junto a grupos isolados de acadêmicos do curso de Odontologia, os quais atuam em atividades extracurriculares, vinculadas aos editais do Programa de Educação pelo Trabalho para a Saúde (PET-Saúde).

A percepção dos formandos sobre a disciplina elencada como estágio supervisionado demonstra uma valoração exacerbada aos aspectos clínicos terapêuticos ou técnico curativistas no campo da Odontologia, minimizando a importância das competências contemporâneas para o ciclo da formação do profissional de saúde, como a tomada de decisões, a comunicação, a liderança, a gestão em saúde e a educação permanente $^{36}$. Na amostra em tela, esta visão pode estar sendo reforçada pela extensa carga horária de atividades clínicas intramuros vivenciadas na estrutura curricular vigente, o que ainda reflete uma visão flexneriana de formação, pouco integradora e biologicista. Ainda que a clínica intramuros seja um equipamento fundamental inserido em disciplinas no currículo, a capacidade e habilidade técnica de tratamento de doenças, foco prioritário deste cenário, não pode ser o único objetivo final na formação dos profissionais de saúde ${ }^{37}$.

Para avançar em sua consolidação, as mudanças na formação em saúde têm estado na agenda da política do Estado, no campo metodológico e pedagógico, com propostas de reestruturação dos currículos e forte articulação como sistema de saúde do país ${ }^{4,6}$, sendo este o momento atual de conformação da estrutura curricular na universidade analisada.

As USF pactuadas pela IES em questão, como campos de estágio acadêmico, possuem localizações geográficas territorialmente dispersasse realidades distintas, sendo inexequível institucionalmente a concessão de transporte para este fim.

A prática da violência intra e extramuros universitária é um fenômeno que vem aumentando nos últimos anos, criando um cotidiano acadêmico aflitivo. A literatura sobre violência é muito ampla, porém o tema, apesar de esgotado quanto à assimilação de seus condicionantes, pouco tem avançado em sua prevenção.

Uma solução proposta pela Universidade Federal do Piauí foi a disponibilização, por parte da universidade, de um segurança e um veículo para o transporte de acadêmicos até o local de estágio ${ }^{38}$. No entanto, entende-se que a sustentabilidade 
dessas práticas deva ser garantida por meio de políticas públicas inter setoriais, das instituições educacionais e da sociedade, no sentido de gerar compromissos e participações acentuadas para a prevenção desse fenômeno.

As DCN permitem certa flexibilização curricular onde cada instituição pode definir a sua carga horária, de acordo com as necessidades pedagógicas. Delinear uma carga horária mínima onde o acadêmico possa se dedicar à Atenção Primária à Saúde durante sua formação é uma experiência realizada por algumas instituições de ensino $^{39}$ e um desafio que acompanha as disciplinas de estágio no SUS.

Com concepção pedagógica inovadora, também quanto à extensão do tempo atribuído às práticas na atenção básica à saúde, a Faculdade de Odontologia da Universidade Federal de Minas Gerais instituiu a disciplina de estágio supervisionado em Odontologia, antes denominado Internato Rural, com carga horária ampla, em torno de 315 horas, a qual tem como objetivo possibilitar ao estudante uma vivencia concreta do SUS e a aproximação com a realidade socioeconômica e cultural da população, integrada à comunidade e ao serviço de saúde local ${ }^{40}$.

Para os formandos pesquisados, as trinta e seis horas dedicadas a atividades de dispersão mostram-se mais do que suficientes, apontando novamente para o desinteresse para com sistema público de saúde e para o sentimento de inadequação como estagiário.

A formação acadêmica voltada para o SUS está bem estabelecida no parágrafo único do artigo $5^{\circ}$ das DCN dos Cursos de Graduação em Odontologia, a saber: "a formação do cirurgiãodentista deverá contemplar o sistema de saúde vigente do país, a atenção integral da saúde num sistema regionalizado e hierarquizado de referência e contra referência e o trabalho em equipe $^{41}$ ".
A representação exposta pelos acadêmicos sugere uma falta de entendimento em relação às competências do egresso de Odontologia; mas pode também estar relacionada à fragmentação de disciplinas e ao modo de organização dos saberes praticado no curso. A extensa carga horária e a valoração atribuída às clínicas intramuros, a descontextualização das necessidades epidemio-lógicas da população e a visão flexneriana de formação que valoriza a compartimentalização do conhecimento também parecem influenciar.

De acordo com as DCN dos Cursos de Graduação em Odontologia, as avaliações do estágio devem se basear nas competências, habilidades e conteúdos curriculares, considerando que o processo de ensino e aprendizagem sofre influência dos meios pedagógicos adotados e das condições em que a prática ocorre ${ }^{42}$.

$\mathrm{Na}$ disciplina pesquisada o método avaliativo é composto por três estratos: avaliação individual pelo professor orientador quanto ao desempenho nas atividades de contextualização; avaliação individual do cirurgião-dentista quanto às habilidades necessárias para o trabalho no SUS; e avaliação em grupo pelo professor orientador do relatório final sobre as vivências no estágio.

Uma vez que o CD preceptor atua conectando estudantes a competências necessárias para a vida profissional e estreita a distância entre teoria e prática na formação acadêmica $^{42,43}$, sua participação torna-se intrínseca ao objeto avaliativo. No entanto, a avaliação por parte dos CD preceptores é apontada como motivo de insatisfação, revelando a desconfiança dos acadêmicos quanto à capacidade avaliativa deste profissional.

Este fato pode estar mais uma vez relacionado à desvalorização dos campos de trabalho e de atuação no SUS, assim como a um 
imaginário cultural acadêmico que emprega à figura do professor uma espécie de monopólio sobre a avaliação e retenção da aprendizagem.

\section{CONCLUSÕES}

A opinião crítica mostrada pelo grupo de acadêmicos sobre o estágio supervisionado no SUS aponta para uma desvalorização na forma atuante do profissional cirurgião-dentista do serviço público brasileiro, assim como, de sua função enquanto preceptor. É ainda explícita a concepção, por parte deles, de que a Odontologia, ainda hoje, é uma profissão isolada em si mesma e extremamente valorizada em suas atividades práticas clínicas de trabalho.

No estágio, as práticas clínicas com pacientes apresentaram o pleno reconhecimento por parte dos acadêmicos, assim como o desejo de que as ações inerentes aos processos de trabalho no SUS assumam caráter voluntário.

Reitera-se que a formação profissional não só se consolida nas atividades denominadas intramuros, com forte apelo teórico e biologicista, mas também na articulação com as demandas de saúde da sociedade.

Nesta perspectiva, os resultados alcançados apresentam subsídios atuais, baseados nas percepções de acadêmicos formandos em Odontologiapara o processo de reestruturação curricular da disciplina de estágio no SUS; os quais apontam para o desenvolvimento de estratégias institucionais voltadas à valorização do SUS e ao diálogo entre as disciplinas, à ampliação das relações entre universidade e serviços de saúde e ao incremento de práticas cuidadoras em saúde, com vistas à qualificação da formação no campo da Odontologia.

\author{
ABSTRACT \\ Constructive critics of Dentistry graduating \\ students to rethink the supervised intership in
}

\section{Unified Health System}

The study aims at obtaining critical perceptions of Dentistry graduating students about the supervised intership in the Unified Health System. An exploratory, descriptive and qualitative research was carried out with the population composed by Dentistry graduating students of a public university in southern Brazil $(n=52)$ (base year: 2016), considering only the ones who judged that the supervised intership in the Unified Health System was not productive for their professional qualification $(n=11)$. The information was apprehended by means of a single guiding question and the results were treated according to the discourse of the collective subject technique. From the information obtained, two themes, 'Organization' and 'Structure' of the supervised intership, and seven central ideas, which originated the discourses, were extracted. The students expose the importance focused on the technicist model of approach, with low interest in the Unified Health System as a field of work.

Descriptors: Dentistry. Unified Health System. Educational Evaluation. Qualitative Research.

\section{REFERÊNCIAS}

1. Fazenda I, Godoy H. Interdisciplinaridade: pensar, pesquisar e intervir. Rev Cien Facerb. 2015; 2(1):45-54.

2. Caggy RCSS, Fischer TMD. Interdisciplinaridade revisada: analisando a prática interdisciplinar em uma Faculdade de Administração na Bahia. Ens Pesq. 2014; 15(3):501-31.

3. Vendruscolo C, Prado ML, Kleba ME. Integração Ensino-Serviço no âmbito do Programa de Reorientação da Formação Profissional em Saúde. Ciênc Saúde Colet. 2016; 21(9):2949-60.

4. Almeida FNM. Contextos, impasses e desafios na formação de trabalhadores em Saúde Coletiva no Brasil. Ciênc Saúde. 2015;18(6):1677-82.

5. Brasil. Constituição da República Federativa do Brasil de 1988. Senado, Brasília: DF. 1988. 
[Acesso em 10 de dez. de 2017] Disponível em: http://www2.camara.leg.br/legin/fed/consti/198 8/constituicao-1988-5-outubro-1988-322142publicacaooriginal-1-pl.html

6. Toassi RFC, Souza JM, Baumgarten A, Rosing CK. Avaliação curricular na educação superior em odontologia: discutindo as mudanças curriculares na formação em saúde no Brasil. Rev ABENO. 2012; 12(2):170-7.

7. Morita MC, Kriger L, Carvalho ACP, Haddad AE. Implantação das Diretrizes Curriculares Nacionais em Odontologia. 2a ed. Maringá: Dental Press. ABENO, OPAS, MS; 2013:160.

8. Ferretti LH, Appel TG, Miguel LCM, Madeira L. Avaliação discente e as Diretrizes Curriculares Nacionais: realidade das clínicas integradas da Univile. Rev ABENO. 2012; 12(2):155-62.

9. Lamers JMS, Baumgarten A, Bitencourt FV, Toassi RFC. Mudanças curriculares na educação superior em Odontologia: inovações, resistências e avanços conquistados. Rev ABENO. 2016;16(4):2-18.

10. Santos KT, Ferreira L, Batista RJ, Bitencourt CTF, Araújo RP, Carvalho RB. Student perceptions about the influence of internship extramural in academic dentistry. Rev Odontol UNESP. 2013; 42(6):420-5.

11. Zilbovicius C. A paradigm shift in predoctoral dental curricula in Brazil: evaluanting the process of change. J Dent Educ. 2011; 75(4):557-64.

12. Schönwetter DJ, Law D, Mazurat R, Sileikyte R, Nazarko O. Assessing graduating dental students' competencies: the impact of classroom, clinic and externships learning experiences. Eur J Dent Educ. 2011; 15(3):142-52.

13. Piskorowski WA, Fitzgerald M, Mastey J, Krell RE. Development of a Sustainable CommunityBased Dental Education Program. J Dent Educ. 2011; 75(8):1038-43.

14. Scavuzzi AIF, Gouveia CVD, Carcereri DL, Veeck EB, Ranali J, Costa LJ, et al. Revisão das Diretrizes da ABENO para a definição do
Estágio Supervisionado Curricular nos cursos de Odontologia. Rev ABENO. 2015;15(3):109-13.

15. Jodelet D. Representações sociais: um domínio em expansão. In: Jodelet D. (Org.). As representações sociais. Rio de Janeiro: Ed UERJ, 2001: 17- 44.

16. Lefèvre F, Lefèvre AMC. O Discurso do Sujeito Coletivo: um novo enfoque em pesquisa qualitativa (Desdobramentos). Caxias do Sul. EDUCS; 2003.

17. Lefèvre F, Lefèvre AMC. O Discurso do Sujeito Coletivo: uma nova abordagem metodológica em pesquisa qualitativa. Caxias do Sul. EDUCS; 2000.

18. Lefévre F, Lefévre AMC. O sujeito coletivo que fala. Comunic Saúde Educ. 2006; 10(20):517-24.

19. Jesus JCM, Ribeiro VMB. Evaluation of the pedagogical training process of preceptors of medical internship. Rev Bras Educ Méd. 2012; 36(2):153-61.

20. Toassi RFC, Davoglio RS, Lemos VMA. Integração ensino-serviço comunidade: o estágio na atenção básica da graduação em odontologia. Educ. 2012; 28(4):223-42.

21. Oliveira ET, Vasconcelos MVL, Rodarte RS, Esteves RZ. Odontologia e preceptoria: um olhar para a prática pedagógica dos preceptores de estágio. Rev Bras Promoç Saúde. 2018; 31(Supl):1-10.

22. Brasil. Lei $n^{\circ}$ 11.788. Dispõe sobre o estágio de estudantes e dá outras providências. Brasília, DF. Diário Oficial da União, Brasília, 26 de set. 2008 [Acesso em 20 de dez. de 2017]. Disponível em: http://www.cvm.gov.br/export/sites/cvm/menu/ acesso informacao/servidores/estagios/3LEGIS LACAO-DE-ESTAGIO.pdf

23. Maciel JAC, Vasconelos MIO, Castro-Silva II, Teixeira AKM, Farias MR, Queiroz MVO. A integração ensino-serviço em odontologia: uma experiência na Atenção Primária à Saúde no município de Sobral, Ceará. Rev APS. 2016; 19(4):650-55. 
24. Faé JM, Silva-Junior MF, Carvalho RB, Esposti CDD, Pacheco KTS. A integração ensinoserviço em Odontologia no Brasil. Rev ABENO. 2016; 16(3):8-17.

25. Caldas JB, Lopes ACS, Mendonça RD, Figueiredo A, Lonts JGA, Ferreira EF, Figueira TR. Students' views of the Educational Program for Health Work. Rev Bras Educ Méd. 2012; 36(2):33-41.

26. Fadel CB, Baldani MH. Percepções de formandos do curso de odontologia sobre as diretrizes curriculares nacionais. Trab Educ Saúde. 2013;11(2):339-54.

27. Lins TS, Soares FJP, Coelho JAP. Avaliação dos atributos em Atenção Primária à Saúde no Estágio em Saúde da Família. Atenção Primária à Saúde no Estágio em Saúde da Família. Rev Bras Educ Méd. 2016; 40(3): 355-63.

28. Pessoa TRRF, Castro RD, Freitas CHSM, Reichert APS, Forte FDS. Formação em odontologia e os estágios supervisionados em serviço público de saúde: percepções e vivências de estudantes. Rev ABENO. 2018; 18(2):14415.

29. Forte FDS. Reorientação na formação de cirurgiões-dentistas: o olhar dos preceptores sobre estágios supervisionados no sistema Único de Saúde (SUS). Interface Comunic Saúde Educ. 2015; 19(1):831-43.

30. Rocha HC, Ribeiro VB. Curso de formação pedagógica para preceptores do internato médico. Rev Bras Educ Méd. 2012; 36(3):34350.

31. Pimentel EC, Vasconcelos MVL, Rodarte RS, Pedrosa CMS, Pimentel FSC. Ensino e aprendizagem em estágio supervisionado: estágio integrado em saúde. Rev Bras Educ Méd. 2015; 39(3):352-58.

32. Matuda CG, Pinto, NRS, Martins CL, Frazão P. Colaboração interprofissional na Estratégia Saúde da Família: implicações para a produção do cuidado e a gestão do trabalho. Ciênc Saúde
Colet. 2015; 20(8):2511-21.

33. Pelisoli C, Sacco AM, Barbosa ET, Pereira CO, Cecconello AM. Acolhimento em saúde: uma revisão sistemática em periódicos brasileiros. Est Psicol. 2014; 31(2):225-35.

34. Lopes AS, Vilar RLA, Melo RHV, França RCS. O acolhimento na Atenção Básica em saúde: relações de reciprocidade entre trabalhadores e usuários. Saúde Debate. 2015; 39(104):114-23.

35. Ribeiro MA, Cavalcante ASP, Teófilo FKS, Albuquerque IMAN, Vasconcelos MIO. Vivências e estágios na realidade do Sistema Único de Saúde (VER-SUS) como agente promotor de mudança na formação de graduação e nas práticas profissionais. Sau Transf Soc. 2016; 7(1):109-19.

36. Lemos CLS. Educação Permanente em saúde no Brasil. Educação ou gerenciamento permanente. Ciênc Saúde Colet. 2016;21(3):913-22.

37. Toassi RFC, Stobaus CD, Mosquera JJM, Moysés SJ. Currículo integrado no ensino de odontologia: novos sentidos para a formação na área da saúde. Interface. 2012; 16(4):529-42.

38. Viena PFS, Adad SJH, Pedrosa JIS. Reverberações das experiências extramuros no ensino da odontologia. Arq Bras Ciênc Saúde. 2015; 40(3):190-96.

39. Grande IMP, Prochnow R, Saab R, Pizzatto E. Desafios na formação do cirurgião-dentista para o SUS. Rev Abeno. 2016; 16(3):2-6.

40. Santa RT, Thalita TA, Vargas AM D, Ferreira EF. O internato rural e a formação de estudantes do curso de Odontologia da UFMG. Interface. 2007;11(23):451-66.

41. Brasil. Ministério de Educação. Diretrizes Curriculares Nacionais dos Cursos de Graduação em Odontologia. Resolução CNE/CES. 2002. [Acesso em 20 de dez. de 2017]. Disponível em: http://portal.mec.gov.br/cne/arquivos/pdf/CES0 32002.pdf

42. Luz GW, Toassi RFC. Percepções sobre o preceptor cirurgião-dentista da Atenção Primária 
à Saúde no ensino da Odontologia. Rev ABENO. Correspondência para: 2016; 16(1):2-12.

Cristina Berger Fadel

43. Bispo EPF. Tavares CHF. Tomaz JMT. e-mail: cbfadel@gmail.com Interdisciplinaridade no ensino em saúde: o olhar Rua Dr. Paula Xavier, 909

do preceptor na Saúde da Família. Interface 84010-270 Ponta Grossa/PR Comunic Saúde Educ. 2014; 18(49): 337-50. 